\title{
Thermal Degradation Kinetics of Isotactic and Atactic Polypropylene
}

\author{
Ravi Kumar, Giridhar Madras \\ Department of Chemical Engineering, Indian Institute of Science, Bangalore, 560 012, India
}

Received 23 August 2002; accepted 17 March 2003

\begin{abstract}
The thermal degradation of isotactic and atactic polypropylene was investigated in bulk and in solution. The degradation in bulk was studied with thermogravimetric analysis, and the degradation in solution was studied by the dissolution of the polymer in paraffin oil. The degradation in solution was investigated from 230 to $350^{\circ} \mathrm{C}$. The effect of the hydrogen donor on the degradation of the polymer in solution was also studied at $350^{\circ} \mathrm{C}$. Continuous
\end{abstract}

distribution kinetics were employed to model the degradation kinetics for the degradation in solution. The rate coefficients were obtained, and the activation energy was calculated from an Arrhenius plot. (c) 2003 Wiley Periodicals, Inc. J Appl Polym Sci 90: 2206-2213, 2003

Key words: isotactic; poly(propylene) (PP); atactic; molecular weight distribution/molar mass distribution

\section{INTRODUCTION}

Commercial polypropylene (PP) is predominantly isotactic. Isotactic polypropylene (IPP) is a stiff, highly crystalline polymer that has the lowest density of the major plastics and possesses a very high strength-toweight ratio. It has a crystalline melting point of $165-$ $175^{\circ} \mathrm{C}$. IPP has good tensile strength, modulus, hardness, stiffness, and so forth and is mainly used as a molding material. Because of its hardness, it is blended with elastomers and used in many applications. Atactic polypropylene (APP) is predominantly amorphous, semitacky, and intermediate between a wax and a rubber. It swells extensively in aliphatic and aromatic hydrocarbons at room temperature. APP is used in conjunction with bitumen in coating compounds for roofing materials and sealing strips, to which it confers improved aging properties, and in road construction, in which it improves the stability of asphalt surfaces.

Polymer degradation is the focus of a great deal of current research into the management of plastic waste. The knowledge of the degradation kinetics of polymers is important for modeling the degradation process. The process of chain scission is very complex and leads to a variety of products. The fragmentation can be either random or specific, depending on the experimental conditions. Pyrolysis is the standard techin).

Correspondence to: G. Madras (giridhar@chemeng.iisc.ernet.

Contract grant sponsor: Indian Department of Science and Technology.

Journal of Applied Polymer Science, Vol. 90, 2206-2213 (2003)

(C) 2003 Wiley Periodicals, Inc. nique used for thermally degrading polymers, and numerous studies have been carried out on the degradation of PP in the bulk. ${ }^{1-3}$ However, degradation by bulk pyrolysis suffers from severe heat- and masstransfer problems because of the high melt viscosity, severe heat-transfer resistance, complex degradation behavior, and undesirable byproduct formation. ${ }^{4}$ This complicates reactor analysis, design, and scale-up. ${ }^{5}$

To overcome these problems, researchers have proposed degradation in solution as an alternative. All products are in a single phase with a much lower viscosity, and this enables better heat transfer, enhanced reaction rates, and improved residence time control. Degradation in solution has been studied extensively for polymeric systems, which are easily soluble under room conditions. ${ }^{5}$ However, work on the degradation of polyolefins in solution is scarce. The degradation of low-density polyethylene (LDPE) in solution was carried out by Kumar et al. ${ }^{6}$ Guy and Fixari ${ }^{7}$ investigated the degradation of high-density polyethylene (HDPE) in solution. Other investigations into PP systems in solution have emphasized the mechanistic aspects of the scission process. ${ }^{8-10}$

The objective of this investigation was to determine the kinetics of IPP and APP in solution. The influence of the hydrogen donor on the scission process was also investigated.

\section{EXPERIMENTAL}

The thermal degradation of IPP [Reliance Industries, India; number-average molecular weight $\left(M_{n}\right)$ $=125,000$ ] and APP (Polysciences, Inc., United States; $\left.M_{n}=30,000\right)$ in bulk was studied in air and nitrogen in a Polymer Labs (United Kingdom) thermoanalyzer. 
The heating rate was kept at $15 \mathrm{~K} / \mathrm{min}$. The heating was carried out from room temperature to $600^{\circ} \mathrm{C}$.

The thermal degradation of IPP and APP in solution was carried out in a closed round-bottom flask equipped with a condenser; $0.2 \mathrm{~g}$ of $\mathrm{PP}$ was dissolved in $100 \mathrm{~mL}$ of liquid paraffin $\left(\mathrm{bp}=360^{\circ} \mathrm{C}\right.$ ) after it reached the desired temperature of $230-350^{\circ} \mathrm{C}$. The liquid paraffin was heated for $5 \mathrm{~h}$ in the absence of the polymer. There was no change in the molecular weight distribution (MWD) of the oil before and after heating. The experimental temperatures were controlled to $\pm 2{ }^{\circ} \mathrm{C}$ precision with a Thermotherm controller (Bangalore, India). Triphenylmethane was used (bp $=360^{\circ} \mathrm{C}$ ) as a hydrogen donor at $350^{\circ} \mathrm{C}$ to investigate the effect of the hydrogen donor on the reaction. Samples were taken at regular intervals and injected into a high-performance liquid chromatography (HPLC)/gel permeation chromatography apparatus. The time evolution of MWD was analyzed by size exclusion chromatography with $o$-dichlorobenzene as an eluent. The HPLC system consisted of an isocratic pump (Waters, Milford, MA), mixed B columns (Polymer Labs, Amherst, MA), and an evaporative light scattering detector (Polymer Labs). The columns were maintained at $150^{\circ} \mathrm{C}$ with an Eldex column heater (Napa, CA), and the system was calibrated with polystyrene standards. The eluent flow rate was kept at 0.7 $\mathrm{mL} / \mathrm{min}$, and the $\mathrm{N}_{2}$ gas flow rate to the light scattering detector was kept at $0.8 \mathrm{~mL} / \mathrm{min}$ for enhanced sensitivity. The molecular weights of PP were determined from the calibration curve based on polystyrene standards with appropriate Mark-Houwink parameters $(K)$ and $\alpha$ values.

\section{THEORETICAL MODEL}

The major elementary steps of thermal degradation are initiation/termination, hydrogen abstraction, isomerization, and propagation/depropagation, as elucidated in the Rice-Herzfeld mechanism. ${ }^{11,12}$ Continuous distribution kinetics are applied to the various steps involved in the scission process. The effect of hydrogen donors is also included in the model. Hydrogen donors may increase, reduce, or have no effect on the degradation rate of polymers, as discussed by Madras and McCoy. ${ }^{13}$

As the polymer reactants and products are not distinguished in the model, a single MWD, $p(x, t)$, represents the polymer mixture at any time $t$. The reacting polymer and the radicals are represented as $\mathrm{P}(x)$ and $\mathrm{R}^{*}(x)$, and their corresponding MWDs are $p(x, t)$ and $r(x, t)$, where $x$ represents the molecular weight. The reactions are represented as follows, ${ }^{14} \Leftrightarrow$ denoting a reversible reaction:

$$
\begin{aligned}
& \mathrm{P}(x) \stackrel{k_{f}}{\Leftrightarrow} \mathrm{R}^{*}\left(x^{\prime}\right)+\mathrm{R}^{*}\left(x-x^{\prime}\right) \\
& \mathrm{P}(x)+\mathrm{R}^{*}(x) \Leftrightarrow \mathrm{P}\left(x^{\prime}\right)+\mathrm{R}^{*}(x) \\
& \mathrm{P}(x) \Leftrightarrow \mathrm{R}^{*}(x) \\
& k_{H} \\
& k_{b} \\
& \mathrm{R}^{*}(x) \Leftrightarrow \mathrm{P}\left(x^{\prime}\right)+\mathrm{R}^{*}\left(x-x^{\prime}\right) \\
& k_{a} \\
& \mathrm{P}(x)+\mathrm{D} \Leftrightarrow \mathrm{R}^{*}\left(x^{\prime}\right)+\mathrm{D}^{*}
\end{aligned}
$$

Reaction A represents the initiation/termination reaction, $k_{f}$ and $k_{t}$ being the initiation and termination coefficients, respectively. Reaction $B$ represents the hydrogen abstraction process (with rate coefficients of $\mathrm{Kh}$ and $\mathrm{KH}$ ) between the polymer radicals, and it can be written as pseudo-first-order reaction $C$ when the concentration of the polymer and the radicals are high. Reaction D represents propagation/depropagation, $k_{b}$ and $k_{a}$ being the propagation and depropagation rate coefficients, respectively. Reaction $\mathrm{E}$ is the hydrogen abstraction step, $k_{d}$ and $k_{D}$ being the rate coefficients for the forward and backward reactions, respectively. $\mathrm{D}$ and $\mathrm{D}^{*}$ represent the hydrogen donor and its dehydrogenated form, respectively. Therefore, reaction $\mathrm{E}$ represents the effect of the hydrogen donor on the system, with the hydrogen donor playing a crucial role in the conversion of the polymer into the radical.

The population balance equations ${ }^{14}$ for $p(x, t)$ and $r(x, t)$ can be written as follows:

$$
\begin{aligned}
& \partial p / \partial t=-k_{f}(x) p(x)+\int_{0}^{x} k_{t}(x) r\left(x^{\prime}\right) r\left(x-x^{\prime}\right) d x^{\prime} \\
& -k_{h}(x) p(x)+k_{H}(x) r(x)+\int_{x}^{\infty} k_{b}(x) r\left(x^{\prime}\right) \Omega\left(x, x^{\prime}\right) d x^{\prime} \\
& -p(x) \int_{0}^{\infty} k_{a}(x) r\left(x^{\prime}\right) d x^{\prime}-k_{d}(x) p(x) C+k_{D}(x) r(x) C \\
& \partial r / \partial t=2 \int_{X}^{\infty} k_{f}(x) p\left(x^{\prime}\right) \Omega\left(x, x^{\prime}\right) d x^{\prime}-2 r(x) \\
& \quad \times \int_{0}^{\infty} k_{t}(x) r\left(x^{\prime}\right) d x^{\prime}+k_{h}(x) p(x)-k_{H}(x) r(x) \\
& \quad-k_{b}(x) r(x)+\int_{X}^{\infty} k_{b}(x) r\left(x^{\prime}\right) \Omega\left(x, x^{\prime}\right) d x^{\prime}
\end{aligned}
$$




$$
\begin{aligned}
& +\int_{0}^{X} k_{a}(x) r\left(x-x^{\prime}\right) p\left(x^{\prime}\right) d x^{\prime}-r(x) \\
& \times \int_{0}^{\infty} k_{a}(x) p\left(x^{\prime}\right) d x^{\prime}+k_{d}(x) p(x)-k_{D}(x) r(x) C
\end{aligned}
$$

The initial conditions are $p(x, t=0)=p_{0}(x)$ and $r(x, t$ $=0)=0$. The stoichiometric kernel for random scission is $\Omega\left(x, x^{\prime}\right)=1 / x^{\prime}{ }^{14}$ When the initiation and termination events are infrequent in comparison with hydrogen abstraction and propagation and depropagation steps, the initiation and termination steps are assumed to be negligible. ${ }^{14}$ Because there is no polymerization, the addition rate coefficient $k_{a}$ can be assumed to be zero. The quasistationary steady-state approximation (QSSA) applies when the rates of change of the radical concentrations are extremely small. It is assumed that the rate coefficients are a linear function of the molecular weight $[k(x)=k x]$. Applying the moment operation on the population balance equation (PBE) and substituting $k_{f}=k_{t}=k_{a}=$ 0 , we obtain

$$
\begin{array}{r}
d p^{(n)} / d t=-k_{h} p^{(n+1)}+k_{H} r^{(n+1)}+\left[k_{b} r^{(n+1)} /(n+1)\right] \\
\quad-k_{d} p^{(n+1)} C+k_{D} r^{(n+1)} C \\
\begin{array}{r}
d r^{(n)} / d t=k_{h} p^{(n+1)}-k_{H} r^{(n+1)}-k_{b} r^{(n+1)} \\
+\left[k_{b} r^{(n+1)} /(n+1)\right]+k_{d} p^{(n+1)} C-k_{D} r^{(n+1)} C
\end{array}
\end{array}
$$

where $C$ is the concentration. Using QSSA, we obtain

$$
d r(x, t) / d t=0
$$

and

$$
d r^{(n)} / d t=0
$$

Equation (4) becomes

$$
r^{(1)}=k_{r} p^{(1)}
$$

where $k_{r}$ is given by

$$
k_{r}=\left(k_{h}+k_{d} C\right) /\left(k_{H}+k_{D} C\right)
$$

Summing eqs. (3) and (4) for $n=1$, we obtain

$$
d\left[r^{(1)}+p^{(1)}\right] / d t=0
$$

which confirms the mass balance. Applying QSSA, we obtain

$$
d r^{(1)} / d t=0
$$

Therefore, eq. (9) reduces to

$$
\begin{aligned}
& d p^{(1)} / d t=0 \\
& p^{(1)}(t)=p_{0}^{(1)}
\end{aligned}
$$

which implies that the mass is conserved. The variation of the zero moment, $p^{(0)}(t)$, is given by

$$
\begin{aligned}
& \frac{p^{(0)}}{p_{0}^{(0)}}-1=k_{r} M_{n 0} t \\
& \frac{M_{n 0}}{M_{n}}-1=k_{r} M_{n 0} t
\end{aligned}
$$

For thermal degradation without a hydrogen donor $(C=0), k_{r}$ reduces to

$$
k_{r 0}=k_{b} k_{h} / k_{H}
$$

Therefore, it can be written as follows:

$$
X_{k r}=k_{r} / k_{r 0}=k_{H}\left(k_{h}+k_{d} C\right) / k_{h}\left(k_{H}+k_{D} C\right)
$$

The previous expression can be modified as follows:

$$
\begin{aligned}
& {\left[C /\left(1-X_{k r}\right)\right]=\left[1 /\left(k_{D} / k_{H}\right)\right.}\left.-\left(k_{d} / k_{h}\right)\right] \\
&+C /\left[1-\left(k_{d} k_{H} / k_{D} k_{h}\right)\right]
\end{aligned}
$$

\section{RESULTS AND DISCUSSION}

\section{Thermogravimetric analysis (TGA)}

Figure $1(a, b)$ indicates that the weight loss of IPP and APP is higher in air than in $\mathrm{N}_{2}$ and that the weight loss starts around $350^{\circ} \mathrm{C}$. Although the onset of the weight loss of PP begins at $230-250^{\circ} \mathrm{C}$, the breakdown leading to volatile products starts only above $300^{\circ} \mathrm{C} .{ }^{15} \mathrm{In}-$ tramolecular radical-transfer and propagation processes account for the volatile products above $300^{\circ} \mathrm{C}$ in PP. ${ }^{16}$ The activation energy for the degradation in bulk is obtained by the Friedman technique, ${ }^{17}$ in which the rate of change of mass is plotted against the inverse of temperature (plot not shown). The activation energy was determined from the slope of the linear plot to be $32 \mathrm{kcal} / \mathrm{mol}$.

\section{Degradation in solution}

The rate coefficients of the thermal degradation of PP in paraffin oil were obtained by an analysis of the MWD. Equations (13) and (14) are equivalent, and so a plot of $p^{(0)} / p_{0}{ }^{(0)}-1$ is equivalent to a plot of $M_{n} / M_{n 0}$ - 1 , where $M_{n \text { o }}$ denotes the initial molecular weight. Figures 2 and 3 show the variation of $p^{(0)} / p_{0}{ }^{(0)}$ with time for the thermal degradation of IPP and APP. $M_{n 0} / M_{n}$ increases to around 2.5 and 12 after $2 \mathrm{~h}$ for APP and IPP, respectively. The inset figures show the variation at shorter times. The scission process at shorter times was rapid and slowed at higher time- 


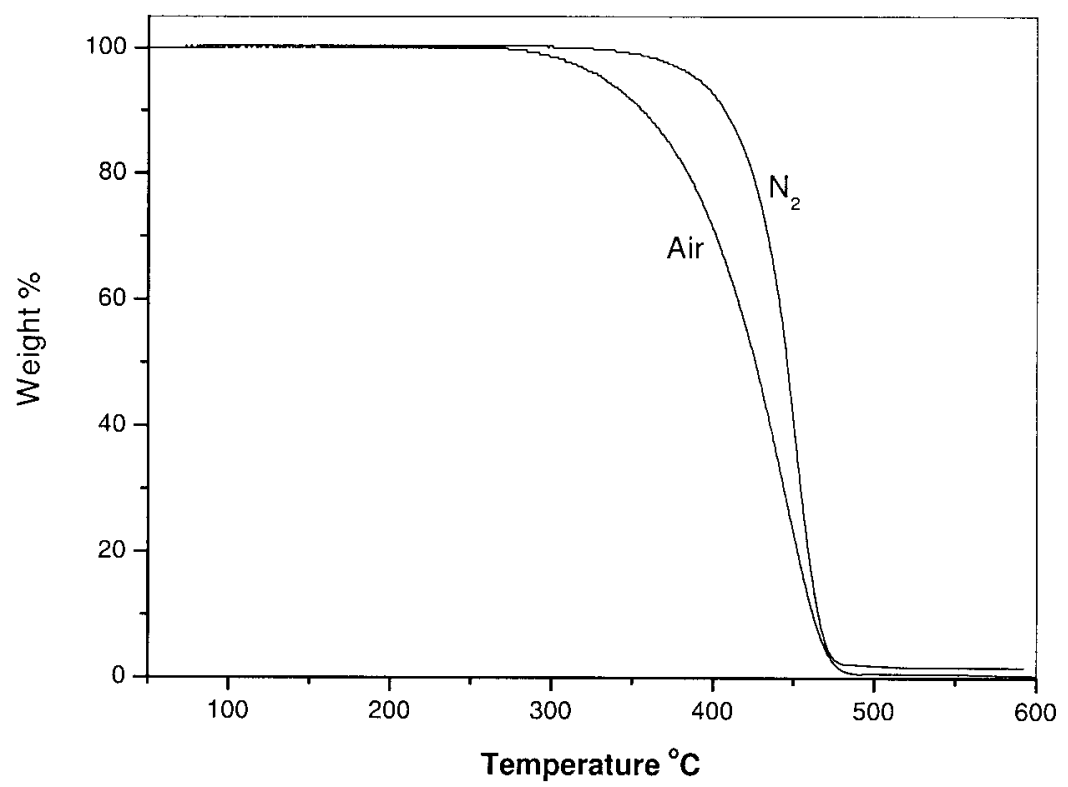

(a)

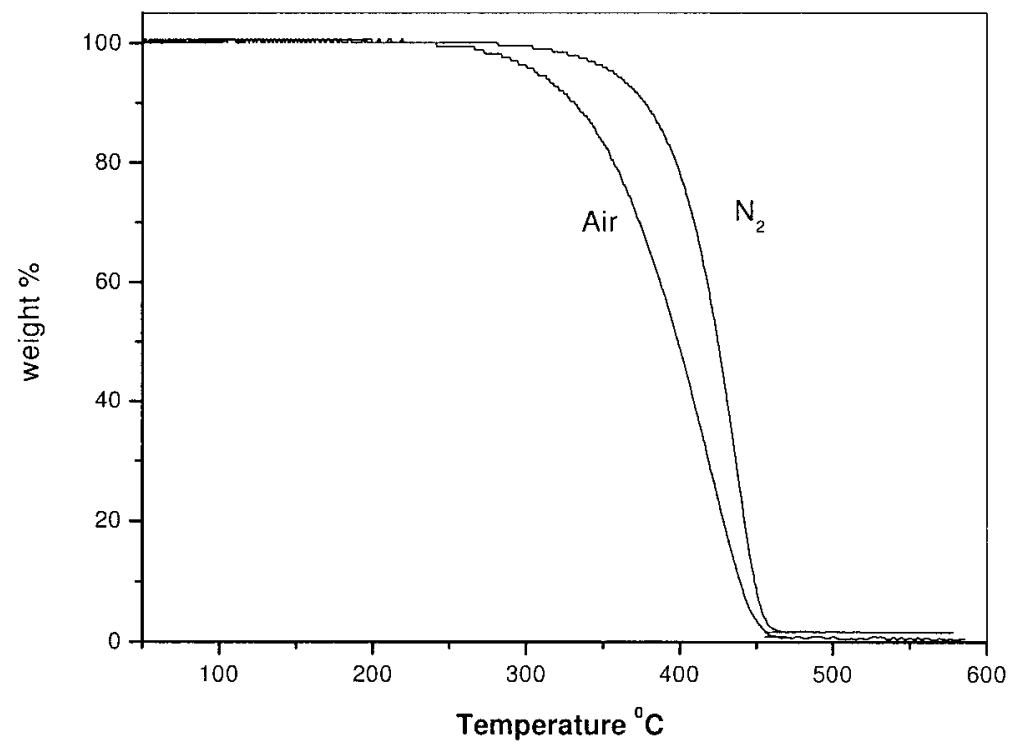

(b)

Figure 1 TGA of (a) IPP and (b) APP in air and nitrogen.

scales. This behavior of rapid initial degradation followed by slower chain breakage has also been observed for LDPE in solution, ${ }^{6}$ HDPE in solution, ${ }^{7}$ HDPE in bulk, ${ }^{18} \mathrm{PP}$ in bulk by TGA, ${ }^{19}$ and polystyrene in solution. ${ }^{20}$

Two stages of breakdown are generally observed in polyolefins. An abrupt decrease in the molecular weight at lower timescales has been attributed to the weak links in the main chain, and volatilization at higher temperatures is due to the depolymerization and hydrogen-transfer process. The rapid reduction of $M_{n}$ at shorter times could be due to scission at branch points or at carbonyl or peroxy linkages. It has been reported that there are 30 branch points for about 1000 carbon atoms in LDPE. ${ }^{6,18}$ Oakes et al. ${ }^{21}$ observed that the molecular weights of branched polymers decreased below $290^{\circ} \mathrm{C}$ with insignificant volatilization.

PP degrades more rapidly at short reaction times than at longer reaction times. Our model assumes the total molar concentration of the polymer to be the sum of the molar concentrations of weak links and strong links. ${ }^{6,20} \mathrm{We}$ assume the concentration of the weak links to be very small, and the initial high breakage rate is due to the weak link breakage. ${ }^{22}$ The rate coefficient at short reaction times corresponds to the weak link scission, and that at higher 


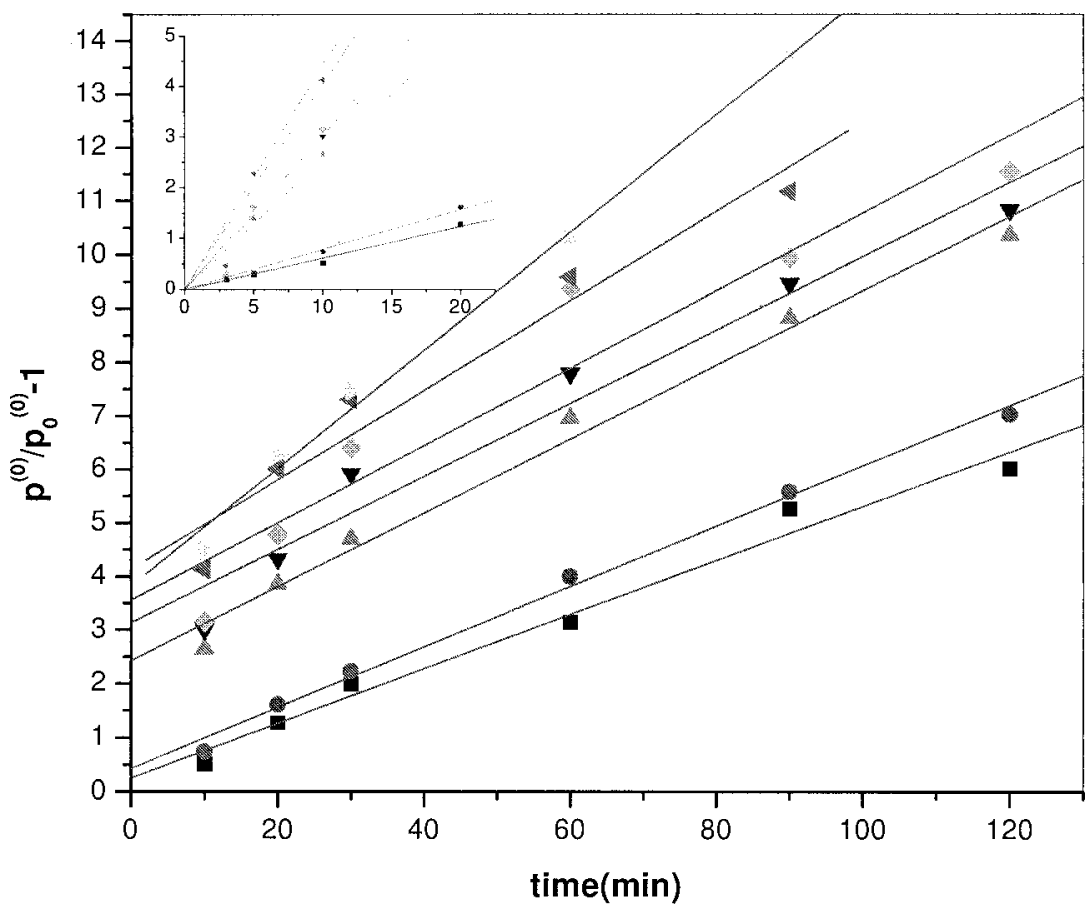

Figure 2 Variation of $p^{(0)} / p_{0}{ }^{(0)}-1$ with time for IPP for the determination of the rate coefficients:

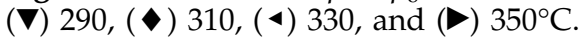

230, (О) 250, (A) 270,

reaction times corresponds to the strong link scission. ${ }^{20}$

The concentration of the weak links is lower than that of strong links ${ }^{20}$ and reaches zero by time $t_{f}$. The molar concentration of the weak-link scission prod- ucts, therefore, remains constant for $t \geq t_{f}$. We infer from Figures 2 and 3 that the weak links are completely depleted by $20 \mathrm{~min}$ for IPP and by $30 \mathrm{~min}$ for APP. The insets of Figures 2 and 3 show the variation of $M_{n}$ with time, with the slopes corresponding to the

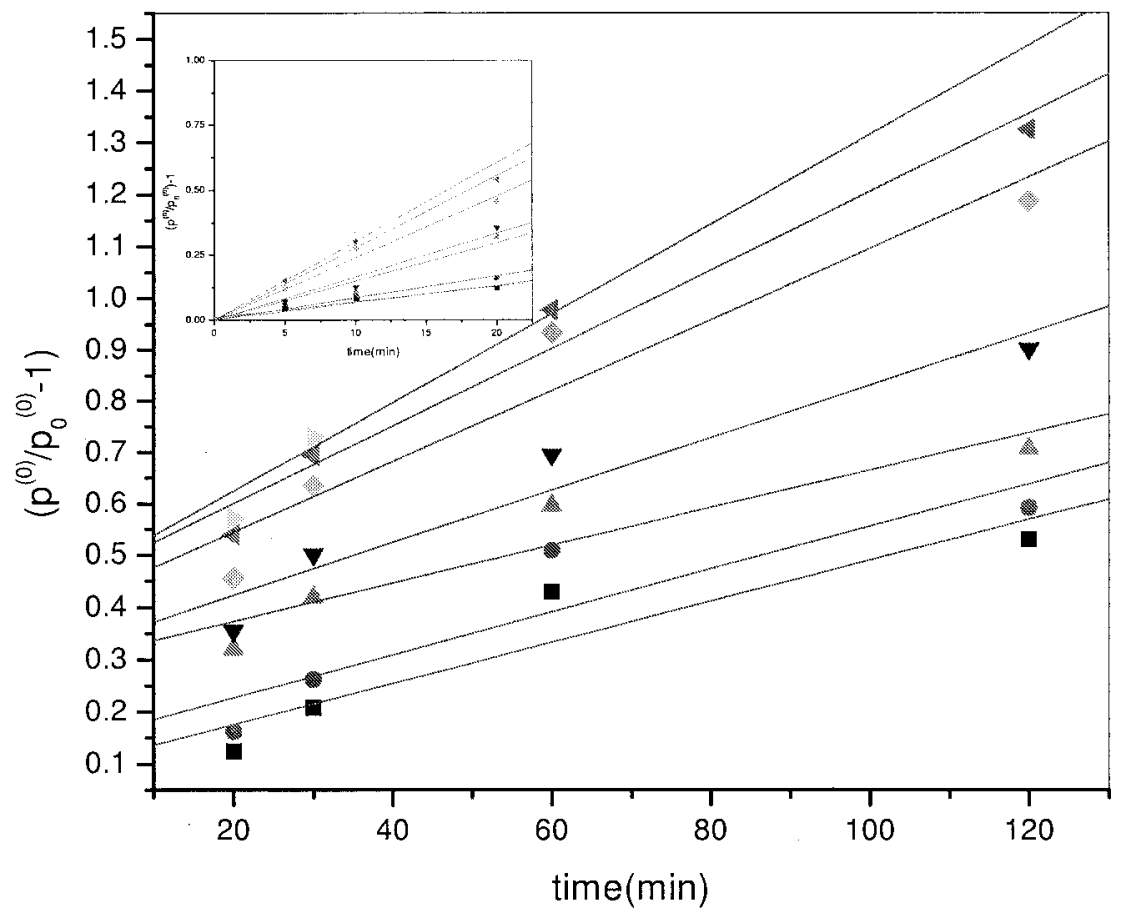

Figure 3 Variation of $p^{(0)} / p_{0}{ }^{(0)}-1$ with time for APP for the determination of the rate coefficients:

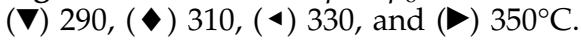




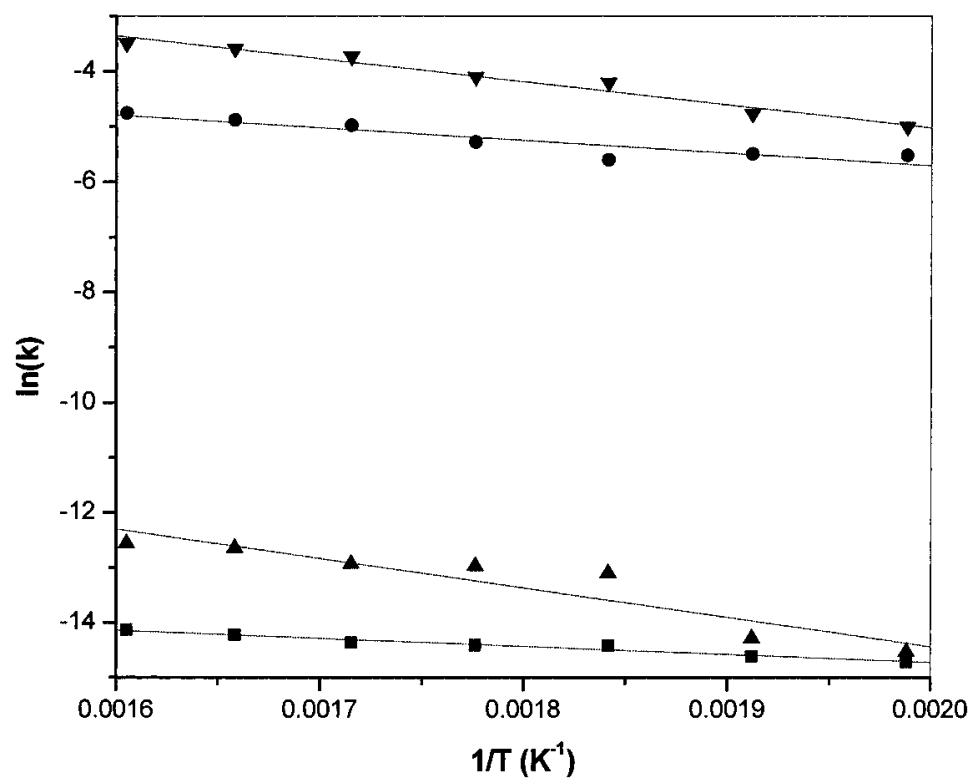

Figure 4 Arrhenius plot of the degradation rate coefficients with temperature for IPP and APP: ( $\mathbf{\Delta})$ weak links for IPP, strong links for IPP, ( $)$ weak links for APP, and $(\mathbf{0})$ strong links for APP.

rate coefficients for the weak links $\left(k_{r w}\right)$. Figures 2 and 3 shows the respective plots for $t>20 \mathrm{~min}$, with the slopes corresponding to the rate coefficients for the strong links $\left(k_{r s}\right)$. The degradation rate coefficients for APP and IPP are obtained with eqs. (1) and (2), respectively. The values of the rate coefficients $k_{r s}$ and $k_{r w}$ vary from 0.0506 to $0.011 \mathrm{~min}^{-1} \mathrm{~g} \mathrm{~mol}^{-1}$ and from 0.0611 to $0.4404 \mathrm{~min}^{-1} \mathrm{~g} \mathrm{~mol}^{-1}$, respectively.

Arrhenius plots of the rate coefficients for IPP and APP are shown in Figure 4, and the activation energy was found to be $2 \mathrm{kcal} / \mathrm{mol}$ for weak links and around $1.5 \mathrm{kcal} / \mathrm{mol}$ for strong links.
The activation energies reported in the literature ${ }^{3}$ for the degradation of PP are considerably higher than this value. The low values for the activation energies indicate that the mechanism of scission is complex, with intermolecular and intramolecular hydrogentransfer steps as the rate-controlling steps. ${ }^{23}$ The activation energy for the intermolecular hydrogen abstraction is $8 \mathrm{kcal} / \mathrm{mol}^{24}$ and the activation energy for the stabilization of the radicals is nearly $0 \mathrm{kcal} / \mathrm{mol}^{25}$ Therefore, both the intermolecular hydrogen abstraction and the radical stabilization play vital roles in the reaction kinetics in the degradation of PP in solution.

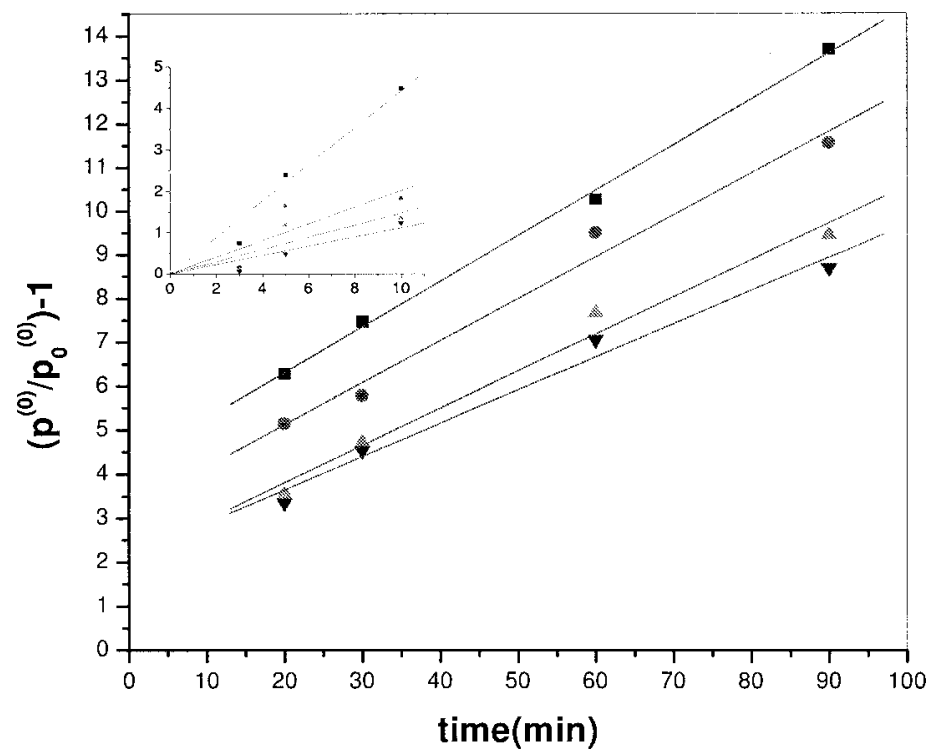

Figure 5 Variation of $p^{(0)} / p_{0}{ }^{(0)}-1$ with time for IPP in the presence of a hydrogen donor at 350 $\mathrm{C}:(\mathbf{\square}) 0,(\mathbf{\Delta}) 20,(\mathbf{\bullet}) 40$, and (v) $80 \mathrm{~g} / \mathrm{L}$. 


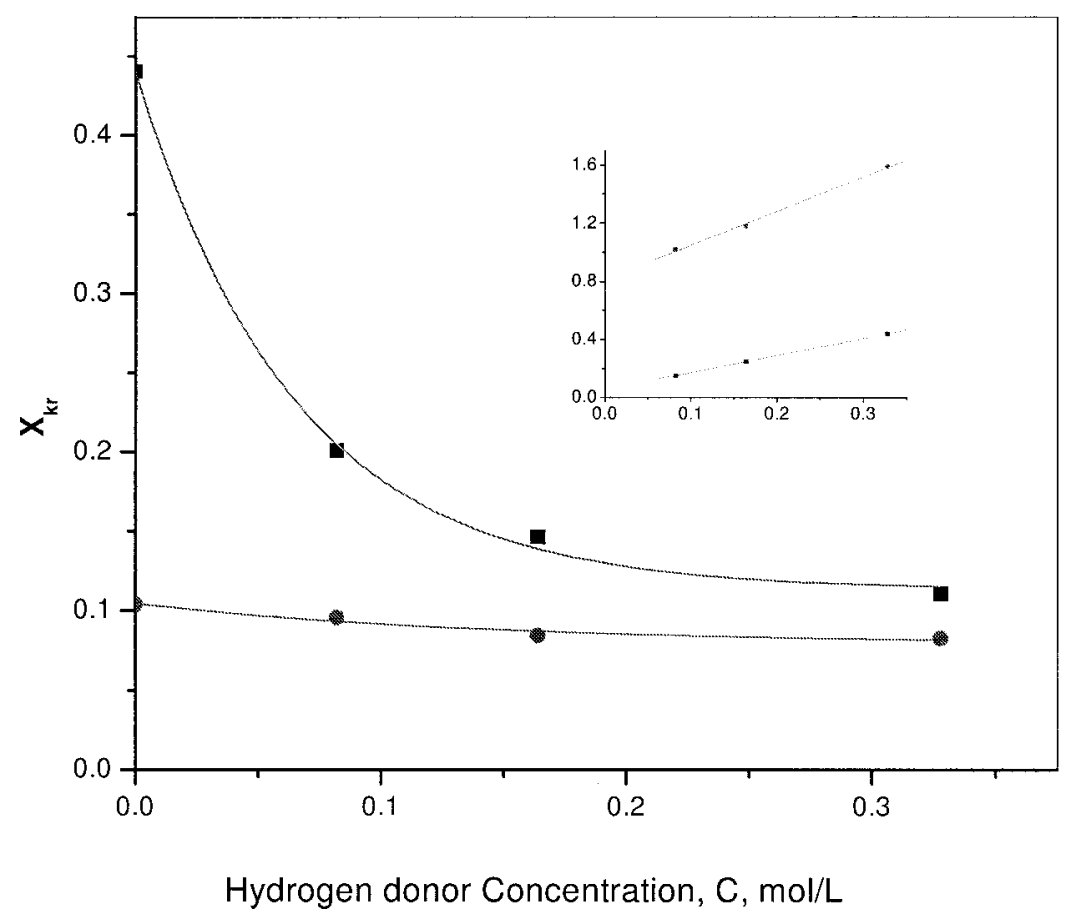

Figure 6 Variation of $k_{r s}(\bullet)$ and $k_{r w}(\boldsymbol{\square})$ with the hydrogen donor concentration at $350^{\circ} \mathrm{C}$. The inset shows the variation of $C /\left(1-X_{k r}\right)$ with $C$, which is linear.

\section{Effect of the hydrogen donor on the degradation kinetics}

Figure 5 shows the time variation of $\left(p^{(0)} / p_{0}{ }^{(0)}\right)-1$ for IPP degradation in the presence of a hydrogen donor. The mechanism primarily involves the breaking of $\mathrm{C}-\mathrm{C}$ chain bonds and the subsequent transfer of the hydrogen atom from the tertiary carbon atom to the site of scission. ${ }^{26}$ The hydrogen donor concentration was varied from 20 to $80 \mathrm{~g} / \mathrm{L}$. As the concentration of the hydrogen donor was increased, the initial rate of breakage decreased, and this confirmed the importance of hydrogen atom transfer in the propagation step. The mechanistic aspect of the scission is as follows:

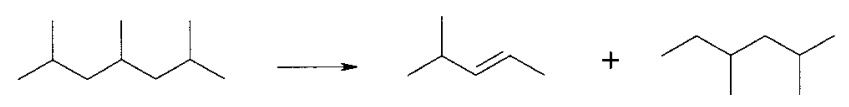

Figure 6 shows a plot of the hydrogen donor concentration versus the rate coefficient. The rate coefficient decreases at higher concentrations and reaches saturation. The inset in Figure 6 shows the variation of $C / 1-X_{k r}$ with $C$, which is linear, as predicted by eq. (17), and the slope of the plot gives the relationship between $k_{D} / k_{d}$ and $k_{H} / k_{h}$, as obtained from the slope of $C / 1-X_{k r}$ versus C. $k_{D} / k_{d}$ was found to be 6 and 1.7 times the value of $k_{H} / k_{h}$ for weak and strong links, respectively.

This study of the role of the hydrogen donor (triphenylmethane) in the degradation of PP, there- fore, indicates that the hydrogen-transfer step seems to be the crucial reaction in the propagation step of the thermal degradation of PP in solution.

\section{CONCLUSIONS}

The degradation of IPP and APP was studied by TGA and in solution. The experimental data indicated that the degradation started around $350^{\circ} \mathrm{C}$ for both APP and IPP in pyrolysis, whereas the degradation started at $230^{\circ} \mathrm{C}$ in solution. The rate coefficients were obtained for the solution degradation by continuous distribution kinetics. The activation energy, determined from the temperature dependency of the rate coefficients, was 1-2 kcal/mol. The effect of the hydrogen donor was also studied, and it was found that the degradation decreased as the concentration of the hydrogen donor increased.

\section{References}

1. Niki, E.; Decker, C.; Mayo, F. R. J Polym Sci Polym Chem Ed 1973, 11, 2813.

2. Decker C.; Mayo, F. R. J Polym Sci Polym Chem Ed 1973, 11, 2847.

3. Westerhout, R. W. J.; Waanders, J.; Kuipers, J. A. M.; Van Swaaij, W. P. M. I\&EC Res 1997, 36, 1955.

4. Murakata, T.; Saito, Y.; Yosikawa, T.; Suzuki, T.; Sato, S. Polymer 1993, 34, 1436.

5. Madras, G.; Smith, J. M.; McCoy, B. J. Polym Degrad Stab 1996, $52,349$.

6. Kumar, S.; Kumar, R.; Madras, G. J Appl Polym Sci 2002, 84, 681. 
7. Guy, L.; Fixari, B. Polymer 1999, 40, 2845.

8. Niki, E.; Shimo, T.; Ido, T.; Kamiya, Y. J Appl Polym Sci 1975, 19, 2341.

9. Osawa, Z.; Saito, T.; Kumira, Y. J Appl Polym Sci 1978, 22, 563.

10. Degtyarova, T. G.; Trofimova, N. F.; Kharitonov, V. V. Polym Sci USSR 1979, 20, 2105.

11. Gavalas, G. R. Chem Eng Sci 1966, 21, 133.

12. Nigam, A.; Fake, D. M.; Klein, M. T. AIChE J 1994, 40, 908.

13. Madras, G.; McCoy, B. J. Catal Today 1998, 40, 321.

14. Kodera, Y.; McCoy, B. J. AIChE J 1997, 43, 3205.

15. Van Scholen, J.; Wijger, P.W.O. In Thermal Degradation of Polymers, Vol. 13; Soc. Chem. Ind.: London, UK, 1961.

16. Tscuchiya, Y.; Sumi, K. J Polym Sci Part A-1: Polym Chem 1969, 7, 1599.

17. Friedman, H. L. J Polym Sci Part C: Polym Symp 1964, 6, 183.
18. Rangarajan, P.; Bhattacharya, D.; Grulke, E. J Appl Polym Sci 1998, 70, 1239.

19. Chan, L.; Balke, E. Polym Degrad Stab 1997, 57, 131.

20. Madras, G.; Smith, J. M.; McCoy, B. J. Polym Degrad Stab 1997, $58,131$.

21. Oakes, W. G.; Richards, R. B. J Chem Soc 1949, 46, 2929.

22. Stivala, S. S.; Kimum, J.; Reich, L. In Degradation and Stabilization of Polymers; Jellinek, H. H. G., Ed.; Elsevier: Amsterdam, 1983; p 1.

23. Chiantore, O.; Camino, O.; Costa, G.; Grassie, N. Polym Degrad Stab 1981, 3, 209.

24. Kerr, J. A.; Trotman-Dickenson, A. F. J Chem Phys 1951, 19, 163.

25. Lehni, M.; Schuh, H.; Fischer, H. Int J Chem Kinet 1979, 11, 709.

26. Madorsky, S. L. Thermal Degradation of Organic Polymers; Interscience: New York, 1964. 